\title{
The Evaluation Analysis of Design Code about the Road Design of longitudinal gradient in the Mountain Road
}

\author{
Yuanxun Zheng ${ }^{1, a,{ }^{*}}$, Huiji Guo ${ }^{2, b, \#}$ and Xiaobing Wei ${ }^{1, c, *}$ \\ ${ }^{1}$ School of Water Conservancy and Environment, Zhengzhou University, Zhengzhou, 450001, China \\ ${ }^{2}$ School of Transportation Engineering, Tongji University, Shanghai, 200092, China \\ ayxzheng@zzu.edu.cn, b287667308@qq.com, ${ }^{\text {c9 } 935880282 @ q q . c o m ~}$
}

*The corresponding author

Keywords: Highway; Continuous long down; Accident rate; Design regulation; Safety evaluation

\begin{abstract}
In recent years the highway develops rapidly in China, by the end of 2014, the total mileage of China's highway has reached 4.3 million kilometers. Among those, the total mileages of the speedway broke through the bottleneck of 110 thousand kilometers - which ranks the first in the world. With the fast development of basic traffic construction, the problem of safety has become more and more significant. However, some highway (especially, the long longitudinal gradient in the mountain area) has the high accident rate, which caused serious casualties and a great loss of social economy. Aim to this condition, the roads with high accident rate were investigated and analyzed in this paper and the reasons caused accident were studied. The research shows that, besides the carelessness of drivers and the deficiency of the vehicles, the phenomenon of continuous long down design was the same character among those mountain roads .Although those design were not beyond the limiting value, but the maximum longitudinal slope length and slope values almost reach the specification limit frequently, so the rationality of the road design regulations on continuous long down in the mountain road is also worthy of consideration. In this paper, based on the project case of the highway from Shizhong to HeXi in FuJian province, the operational safety of this road was estimated based on the security analysis method of USA, the study shows that, the highway's parameter on the longitudinal gradient is in accordance with Chinese design regulations, but according to the, the danger coefficient is very high in this section of accident highway, which dues to frequently traffic accident. In conclusion, the design regulations of the highway should be improved gradually to assure the traffic safety of highway.
\end{abstract}

\section{Introduction}

Since the 21 st century, the transportation infrastructure of China has been in a vigorous developing period. During this period, the construction of highway has made great progress, the development of the highway began in 1988 when the first speedway from Jiading to Shanghai was put into use, and till the year of 2012 the total mileages had reached 960 thousand kilometers, which exceeded the United States to become the first in the world. With the rapid development of highway, road traffic safety problem is become particularly important. In 2010, the Ministry of transport issued a notice on" the safety risk assessment system for highway bridges and tunnels in the preliminary design stage" ([2010]175), which in order to enhance the safety risk awareness, optimize the project construction plan, improve the safety of construction and operation. However, among the most operation of the highway, some sections of highway occur accidents frequently, which always caused serious casualties and economic losses; the phenomenon has gradually attracted the attention of scientific research workers and relevant management departments. Based on the statistical analysis of traffic accidents, the Ministry of Public Security announced the 10 most dangerous highways in 2013[1], as shown in Table 1.

Based on the analysis of the cause of the above highway traffic accidents, it is found that the design of continuous long downhill is a common feature of the above sections, except for people, vehicles and other factors. Whether this kind of design will cause the accident and the scientific and reasonable design of this section is also worth pondering and discussing. 
Table 1 The 10 dangerous highways

\begin{tabular}{|c|c|c|c|c|}
\hline \multicolumn{5}{|c|}{ The 10 Dangerous Sections Of Highways } \\
\hline Province & Name of the section of highway & $\begin{array}{c}\text { The } \\
\text { Length/km }\end{array}$ & $\begin{array}{c}\text { The Opening } \\
\text { Time }\end{array}$ & Death toll \\
\hline Shanxi & Speedway of Xuegongling Yinchuan province, from $934 \mathrm{~km}$ to $964 \mathrm{~km}$ & $30 \mathrm{~km}$ & $2005 / 1$ & 54 \\
\hline Fujian & Speedway of Xiarong in Hexi direction from $121 \mathrm{~km}$ to $107 \mathrm{~km}$ road & $14 \mathrm{~km}$ & 2004 & 108 \\
\hline Jiangxi & The highway of Jiuma from $6 \mathrm{~km}$ to $22 \mathrm{~km}$ & $16 \mathrm{~km}$ & $2010 / 4$ & 48 \\
\hline Henan & The highway from Zhengzhou to Kaifeng & $44.2 \mathrm{~km}$ & 2006/11 & 55 \\
\hline Guangxi & 316 interprovincial highway from $107 \mathrm{~km}$ to $107.6 \mathrm{~km}$ & $600 \mathrm{~m}$ & $2002 / 1$ & 18 \\
\hline Yunnan & The high of Songdai from $57 \mathrm{~km}$ to $78 \mathrm{~km}$ & $21 \mathrm{~km}$ & 2003/12 & 158 \\
\hline Gansu & 215 National Road from $231 \mathrm{~km}$ to $256 \mathrm{~km}$ & $25 \mathrm{~km}$ & 2011/11 & 24 \\
\hline Qinghai & A grade highway of Huangdao from $48 \mathrm{~km}$ to $98 \mathrm{~km}$ & $50 \mathrm{~km}$ & 2003/9 & 152 \\
\hline Shaanxi & 107interprovincial highway among Changan section from 91 to $131 \mathrm{~km}$ & $40 \mathrm{~km}$ & 2004/12 & 123 \\
\hline Shaanxi & The speedway of Xihan among Xian section from $1136 \mathrm{~km}$ to $1158 \mathrm{~km}$ & $22 \mathrm{~km}$ & $2007 / 9$ & 139 \\
\hline
\end{tabular}

Based on the analysis of the cause of the above highway traffic accidents, it is found that the design of continuous long downhill is a common feature of the above sections, except for people, vehicles and other factors. What's more, traffic accidents often occur in the long downhill section. Although the designs are in line with the design standards, because of the limit of the terrain and economic conditions, a combination of bends and steep slopes, continuous long downhill phenomenon, the maximum slope length and maximum gradient value frequently approximate the limit of longitudinal gradient, the road operation safety has become very poor. Whether this kind of design will cause the accident and the scientific and reasonable design of this section is also worth pondering and discussing.

Taking the highway between Shizhong to Hexi in Fujian province as the typical example, this paper systematically analyzes the causes of the accident. And based on the foreign safety evaluation theory, the safety factors of the those road were analyzed to evaluate its operational safety, and as a result to provide a reference for the design of similar sections in the future, so as to avoid the recurrence of tragedy.

\section{The Factors Analysis for Frequent Accidents Highway in the Hexi Section}

Among the top 10 dangerous highways announced by the Ministry of Public Security in 2013, Xiarong highway and Hexi direction section from $121 \mathrm{~km}$ to $107 \mathrm{~km}$ on the list. This $14 \mathrm{~km}$ long downhill road, located at the junction of Zhangzhou and Longyan. The top of this slope is Shizhong town of Longyan city, and the bottom of the slope is Hexi town of Nanqing county of Zhangzhou city. Since the opening of the road in 2004, the accident caused the death population was 109. Particularly, the "3.22" accident also happened in this section on March 22nd,2013, which resulted in 12 dead and 34 injured, the direct economic losses about 5.2 million yuan in ${ }^{[2,3]}$. The incident caused wide concern in the community. From then on it has become the dreaded "devil" section. As following is the road accident data statistics over the years [2]: 
Table 2 Accident statistics of Hexi section

\begin{tabular}{cccccccccccc}
\hline & \multicolumn{4}{c}{ Hexi section } & \multicolumn{4}{c}{ The accident index of Hexi section accounted } \\
Year & $\begin{array}{c}\text { Total } \\
\text { accident }\end{array}$ & $\begin{array}{c}\text { General } \\
\text { accident }\end{array}$ & $\begin{array}{c}\text { Simple } \\
\text { accident }\end{array}$ & $\begin{array}{c}\text { Spot } \\
\text { mediatio } \\
\mathrm{n}\end{array}$ & $\begin{array}{c}\text { Death } \\
\text { toll }\end{array}$ & $\begin{array}{c}\text { Death } \\
\text { toll }\end{array}$ & $\begin{array}{c}\text { Total } \\
\text { accident } \\
(\%)\end{array}$ & $\begin{array}{c}\text { General } \\
\text { accident } \\
(\%)\end{array}$ & $\begin{array}{c}\text { Simple } \\
\text { accident } \\
(\%)\end{array}$ & $\begin{array}{c}\text { Death } \\
\text { toll(\%) }\end{array}$ & $\begin{array}{c}\text { Death } \\
\text { toll(\%) }\end{array}$ \\
\hline 2005 & 118 & 17 & 26 & 75 & 14 & 16 & 36.1 & 42.5 & 19.7 & 66.67 & 45.7 \\
2006 & 120 & 12 & 17 & 90 & 7 & 12 & 32.7 & 31 & 9.4 & 63.64 & 25.5 \\
2007 & 102 & 11 & 31 & 60 & 11 & 28 & 31.4 & 23.4 & 39.2 & 55 & 63.6 \\
2008 & 301 & 14 & 29 & 258 & 15 & 13 & 61.3 & 51.9 & 23 & 68.2 & 30.3 \\
2009 & 239 & 13 & 77 & 149 & 10 & 20 & 48.2 & 50 & 23.48 & 76.92 & 60.61 \\
2010 & 217 & 19 & 118 & 80 & 13 & 29 & 48.1 & 48.12 & 33.81 & 76.47 & 73.33 \\
2011 & 203 & 14 & 150 & 39 & 11 & 9 & 45.8 & 66.66 & 44.8 & 52.4 & 62.5 \\
2012 & 26 & 3 & 23 & - & 1 & 4 & 40.6 & 100 & 43.25 & 100 & 100 \\
Total & 1326 & 104 & 471 & 751 & 82 & 131 & 44.8 & 44.44 & 29.54 & 65.07 & 51.75 \\
\hline
\end{tabular}

In order to find the reasons that make accidents happen frequently, taking the highway Hexi section as the research object, the causes of the accident was studied systematically in this paper; the study results can provide a reference for the design of similar sections in the future, so as to avoid the recurrence of tragedy.

The Factor Analyzed of Frequent Accidents in the Hexi Section. The analysis of the related literature ${ }^{[2,4]}$ indicates that the high accident rate was caused by three different elements: the human factor, the line shape of the highway, and the factor of the vehicles involved.

The Human Factor. Statistical data of the accidents [2] indicates that over $90 \%$ of drivers involved in the incidents were not local and were not familiar with road condition. The accidents were caused because in long downhill road the drivers would use their brakes too frequently, what more, improper design of road line often misunderstood drivers such as while they had finished the gradient after they reached the bottom of the first long gradient - which made them turn to the high gears, because of the unfamiliar road conditions, their vigilance was not as strong and they were unaware of the risk of the continuous long down. Those behaviors caused the brake system to start shutting-down, which final resulted in the accidents.

The Unsafe State of the Vehicle. Vehicle safety is one of the key causes of traffic accidents. Data statistics show [2 10] that over 90\% of the vehicles involved in the accidents are trucks. Heavy braking system of trucks is always cause by heavy load. If there is a defect in the vehicle's braking system without timely maintenance, braking failure occurs easily in poor road.

Correlation analysis shows that the prominent contradictory exists between the current road design specifications and situation of road transport. The relevant provisions of the existing "People's Republic of China on Road Traffic Safety Law" is based on national security technology as a standard design of the vehicle, while the vehicle load during transport is the "eight ministries and commissions" on the basis of the provisions of the overrun . In order to reap more benefits, the overloaded transportation vehicle was widespread among operators. Data show that the 5 tons load vehicle actually carrying loads is always about 4.6 times, load 10 tons of vehicle load actual loads of about 3.2 times. The heavily overloading increases the vehicle braking system load, especially in the long gradient running, frequent and continued long gradient deceleration, it is easy to cause the brake drum brake temperature arise, resulting in weakening or failure occurs, and induced traffic accident.

The Insecurity Factor of the Line Shape of Road. Considering the design of this section, the design speed of this section is $60 \mathrm{~km} / \mathrm{h}$. At the premise of the design speed, the average point of the longitudinal grade reached $3.35 \%$; 5 points of the longitudinal grade of this section are more than $5 \%$, and one of the longitudinal grades reached 6\%. What's more, taking the means of transportation into consideration, there are 4 tunnels, 12 corners, and a bridge $5 \mathrm{~km}$ long. Taking the 
terrain of this section into consideration, the leveling difference of the entire terrain is 486 meters; the maximum distance from the ground of the bridge is about 90 meters. The longest tunnel is 2640 meters long and the minimum turning radius of the highway is 205 meters. The above design and construction features make this section a complicated highway which integrates the bridge, the turning, the tunnel, and the downhill as a whole. The continuous long down of $14 \mathrm{~km}$ of the Hexi section was dangerous, with the addition of the existence of the bridges, tunnels, and the curved, limited the field of vision for the drivers, all of those reduced the safety factor of the road.

The Relevant Safety Measures for Hexi Section. For the frequently accidents of Hexi section after built, the related departments had taken steps to reduce accident rate for this road[2 8]' included upgrade and improvement of the road structure and facilities, the addition of signs, road speed limit, specific measures were as follows:

(1) Add road warning signs, improve the middle of the anti-collision guardrail barrier (general response: the actual accident rate has not decreased significantly);

(2) Before entering the road, giving the driver a warning card to improve the driver's awareness of safe driving, prevent traffic accidents;

(3) To improve the slope of the service area of the top, and facilitate the inspection of heavy trucks, etc., to avoid the brake system failure and overload factors; At the slope top make the water points, making the passing vehicle brake drum physical cooling;

(4) Restructuring hedge lanes, improve the safety factor hedge lane;

(5) Strict control of overweight behavior, limit the tonnage of heavy truck traffic;

(6) After the Xiarong highway Hexi section "3.22"major road traffic accident happened, Xiarong highway Hexi section has begun to set up the middle isolation facilities. That made the two lane instead of original single lane traffic, so that the vehicle deceleration (although the fact that this measure reduces the traffic accident rate, but greatly impact the road traffic capacity, traffic rate dropped significantly, highway didn't it work anymore , people complained all the time );

(7) In April 10, 2015, Xiarong highway Hexi section carried out "double lane physical isolation and limit speed by vehicle kinds" According to the new record, of the two lanes isolated in the middle by cement pier and fence "hard". Among of this section Longyan road from the entrance of Wushishan tunnel, isolation Pier Road is made by cement, cement pier spacing is 3-4 meters. But the territory of Zhangzhou road from the entrance of Jianan tunnel, road isolation change into the closed cement proof wall. After isolation, bus, car go left lane, lane width of 3.5 meters, the speed limit of $80 \mathrm{~km} / \mathrm{h}$; truck go right lane, lane 3.5 meters wide, which can meet the needs of traffic, the speed limit $40 \mathrm{~km} / \mathrm{h}$ (although compared measures 6 , the pass rate improves, but it was still a temporary solution).

These measures above in the short term reduce the accident rate of the road in some degree. But the facts proved that these measures are taken at present, is a passive auxiliary measure, cannot fundamentally solve the high incidence of Xiarong highway and does not affect its capacity, only change the line can solve the problem. In view of this, through argumentation, in April 10, 2014 the "devil's road" Xiamen Chengdu Expressway and Xi Long Downhill decided to implement the expansion line, and had been approved by the National Development and Reform Commission. The original two-way 4 lane road would be converted to the direction of Zhangzhou Longyan uphill lane. And on the other hand, build a new way of U-shaped, using methods of switch-back curve to slow down the slope so as to achieve a permanent cure effect, which do work for Longyan to Zhangzhou direction.

\section{The Analysis of the Linearity of the Hexi Section Based on "Code for highway route design"}

Linear Analysis of Hexi Section Highway. Considering the frequent accidents of the Hexi section, as a designer of highway it is necessary to analyze the line index of this section based on "Code for highway route design" to study whether its design is rational and scientific or not.

Although it is necessary to consider the limit of speed and the capacity of the speedway, taking the large drop of this section into account, the design speed of this section of $60 \mathrm{~km} / \mathrm{h}$ is consistent with the regulations of "Code for highway route design". Considering the safety of driving, the 
longitudinal grade of the speedway of China should not exceed 5\%; in exceptional circumstance it can reach $6 \%$. However, the longitudinal grade of 5 points of this section is more than $5 \%$ and one of the longitudinal grades reaches $6 \%$, which is consistent with the regulations of China, but design index multiple approach specification limit. What's more, considering the coordination of the design of the bridge, ramp way, and the layout of the whole section, Chinese "Code for highway route design" determines that the longitudinal grade of the bridge can't exceed 4\%, the longitudinal grade of the ramp way of the bridge can't exceed 5\%, and the longitudinal grade of the tunnel must be between $0.03 \%$ and 3\% - which does not limit the tunnel less than 100 meters. Under the restriction of these factors, in spite of the fact that the design of this section was consistence with the regulations, there is no doubt that the many limited indexes in the $14 \mathrm{~km}$ decrease the compatibility of this section and increase the rate of an accident.

Table 3 National standard for highway maximum longitudinal grade

\begin{tabular}{ccccccccc}
\hline The design & speed $(\mathrm{km} / \mathrm{h})$ & 120 & 100 & 80 & 60 & 40 & 30 & 20 \\
\hline The maximum longitudinal grade $(\%)$ & 3 & 4 & 5 & 6 & 7 & 8 & 9 \\
\hline
\end{tabular}

Table 4 National standard for maximum grade line limit of $60 \mathrm{~km} / \mathrm{h}$

\begin{tabular}{|c|c|c|c|c|}
\hline \multicolumn{5}{|c|}{ The design speed is $60 \mathrm{~km} / \mathrm{h}$} \\
\hline the longitudinal grade $(\%)$ & 3 & 4 & 5 & 6 \\
\hline maximum grade line limit(m) & 1200 & 1000 & 800 & 600 \\
\hline
\end{tabular}

What's more, this section used the method of natural linearity, took the long downhill as the main section, and used the natural landform in the maximum degree - which was the best plan in the aim of finances and construction. However, from the perspective of the security assessment, there were some deficiencies in the linearity of this section. It is should set the easement curve at the maximum slope strength, according to the regulations, to reduce the load of brake assembly brought by the long slope. However, accidents usually happened after the easement curve because easement always made driver careless and relax vigilance. Taking the capacity of the speedway into consideration, it is normal for designers to avoid the back curve, but usually the existing of the long and steep slopes always caused high accident rate.

The Safety Assessment of HeXi Road Section. European research institute has done on the long longitudinal safety assessment test [4], in the research, 22 representative long steep freeways were selected as research object, and the average gradient and slope length were looked as variables to study the driving risk of vehicle for the reasons that these two variables had significant effect on severity and frequency of accidents. The study shown that when $d^{*} p \geq 130$ and $p \geq 3 \%$ (Where $d$ is the total grew longitudinal slope length, $\mathrm{m}$; $\mathrm{p}$ represents an average slope of large longitudinal slope, \%), the number of accidents on the ramp increased with the increasing of $d * p$ value. When $\mathrm{p} \leq 3 \%$, the $\mathrm{d} * \mathrm{p}$ value can be negligible. The road of Hexi section is about 14 kilometers, with an average gradient of $3.35 \%$; thereby the risk value can be evaluated as following:

$\mathrm{P}^{*} \mathrm{~d}=469$

Regards to the above results, it is not too hard to find that this road has extremely high driving risk coefficient. In addition, the study shows that:

(1)In contrast to Specification/ Standard, grew longitudinal average slope design should be used to reduce the risk factors.(2) In the long downhill section, the should be avoided insertion, the study concluded that driving on the ramp, the drivers are very cautious, driving speed is generally low, but drivers will be vigilant while they encounter in transition curve of the road, then the vehicle again into the steep slope is easy to occur accident.(3)Avoid the use of small radius curve (refer to set ultra-flat curve) grew up in a longitudinal section.(4)Linear design should provide good visual conditions.(5)Conspicuous warning signs need to be provided in the dangerous sections(6)Provides high amount of hedge lanes in the dangerous area. (7)Climbing lanes and chronic lanes may help to avoid rear-end event.

On the other hand domestic research also confirmed that the average length of downhill brings 
dangers[5,6],for example: the formula of key Laboratory of Road and Traffic Engineering of Ministry of Education of Tongji university corrected the United States GSRS(Grade severity Rating System)'s brake drum temperature prediction model :

$$
F=1.2966 H-14.558 L+102
$$

(Assuming that the conditions for the gross vehicle weight is $60 \mathrm{t}$, the speed of truck is $60 \mathrm{~km} / \mathrm{h}$, the initial temperature of brake drum is $102^{\circ} \mathrm{C}$, the impact of the auxiliary brake mode is not considered , where $H(\mathrm{~m})$ is elevation, $L(\mathrm{~km})$ is slope length)

Based on the formula, the temperature of truck brake drum will reach about $528{ }^{\circ} \mathrm{C}$ from the Hexi section to its slope bottom. Data show [7] when the brake drum temperature is lower than temperature limit of $\theta_{\text {lim }}$, the safe brake is ensured during driving. In Grade Severity Rating(GSRS) of USA, for all the quality and speed trucks use a single $\theta_{\text {lim }}\left(216^{\circ} \mathrm{C}\right)$, for World Road Association "Road Safety Manual", the limited temperature is $260{ }^{\circ} \mathrm{C}$. It can be seen that for the long downhill section of Hexi the brake system temperature of trucks arise rapidly, and which is much larger than the limited temperature, as a result, there is a great truck braking systems security risks during downhill.

\section{The Shortcomings and Prospects of Current "Highway Route Design Code" of China}

According to the current specification about the application of longitudinal slope value, the highest longitudinal slope value and highest value of different slopes should be avoided in different levels of highway, unless it is aim to get the best use of the vantage ground or keep away from the situation like difficult areas of the project.

Furthermore, as the related articles [5 10] stated, "Specification of the highway route design"(JTG D20-2006) ruled the design indexes about the average longitudinal slope, however it only gave the stipulation about the road of level 2, 3 and 4, without the highway. The study results show that the continuous use of several limits indexes and the overlarge average slope of long and steep longitudinal slope were the one of major causes of frequent accidents of Hexi section. In order to avoid this phenomena occur, the standard of China should be strictly limited in the maximum slope and the average slope gradient to improve the compatible and safety of road design.

As related data reported that China own $1.9 \%$ of the entire vehicle in the world, compared with $15 \%$ of death in all the accident, so what cause so high death rate is necessary to be studied. With the improvement of China's comprehensive national strength, the road design concept of China went through three stages since the founding of china. The first stage from 1950s to 1970s, "economic" became the main concept as Chinese economy was not strong enough. The second stage began form the reform and opening-up policy to 1990s, in the background of overall construction, the concept "fast, safe, economic and comfortable" formed at that time. From 1990s till now, Chinese economy has made significant achievements, the concept change to "fast, safe and comfortable" , people-oriented is advocated. Therefore, in the future, the designers should put the road safety, comfort and some such humanization indexes into the design concept, and constantly optimize and improve the design and construction standards, improve the safety of China's road and inclusive, finish the changing from "quantity" to "quality".

\section{Acknowledgements}

This work was supported by Natural Science Foundation of Henan (Grant Nos. 51508114) and Science and Technology Program of Communications Department of Henan Province (No. 2014K37-2), the authors are very grateful to the test field support of Communications Department of Henan Province. The authors thank the advice and support of Dr. Pan Ernian at The University of Akron. Special thanks are extended anonymous reviewers for their value comments.

\section{References}

[1] Information on http://baike.haosou.com/doc/7361698-7628827.(In Chinese) 
[2] J.J Ye, M.J Ye: Safety and Health, (2012) No.20, p54. (In Chinese)

[3] Information on http://mn.sina.com.cn/news/m/2013-11-29/154165853.html(In Chinese)

[4] Z. Wang, Z.N Sun and H.J Zhang: Highway, (2008) No.09, p.59. (In Chinese)

[5] L.Y Zhuang :Highway and Transportation Research, (2011) No.08, p.159. (In Chinese)

[6] R. Fu, Y.S. Guo and W. Yuan: China Journal of Highway and Transport, Vol.22 (2009) No.03,p.101.(In Chinese)

[7] Y. Yuan, C.B. Hu and J.R Shen : Journal of Fuzhou University, Vol.37 (2009) No.06,p.896. (In Chinese)

[8] L. K Shen. Built new ground, "the devil links" hard killer. China Work Safety News. 2014(In Chinese)

[9] World Health Organization. Global status report on road safety: time for action(World Health Organization, 2009).

[10]De Blaeij, Arianne, et al: Accident Analysis \& Prevention, Vol.35(2003) No. 6, p.973-986. 